\title{
Lei e Administração: Encontros e Desencontros ${ }^{1}$
}

\author{
Law and Administration: Meeting and Clashes
}

\author{
Bernardo Sordi ${ }^{1}$ \\ ${ }^{1}$ Università degli Studi di Firenze, FI, Itália
}

Tradução de

\section{Arthur Barrêtto de Almeida Costa}

Resumo: O objetivo do texto é identificar as principais características que o princípio da legalidade assume na modernidade, com especial foco nos desenvolvimentos ocorridos na Europa continental durante o século XIX. Identificam-se três etapas maiores: a legalidade-potência, a legalidade-garantia e a legalidade-sistema. A primeira ocorre durante a época da Revolução Francesa. A segunda vai do período imediatamente posterior até meados do oitocentos. O terceiro período vai de meados do oitocentos até princípios do novecentos. Ressalta-se que as diferentes etapas se sobrepõem e deixam marcas na definição do direito administrativo. Por fim, é individualizado o século XX, marcado pela constitucionalização da administração e pelo controle da própria lei, e a legalidade contemporânea, que surge por exigências mais pesadas que vão além da conformidade com a lei para alcançar as próprias justificações dos atos administrativos.

Palavras-chave: Legalidade. Administração Pública. Século XIX.
Abstract: The paper aims to identify the main characteristics of the principle of legality during the modernity, focusing especially on the developments of continental Europe during the 19th century. The author individualizes three main steps: legality-power, legality-guarantee and legality-system. The first one happens during the French Revolution. The second one spans over the period from right after that until mid-nineteenth century. The third period starts on mid-nineteenth century and goes until the beginning of the 20th century. It should be stressed that the different steps overlap themselves and leave traces on the definition of administrative law. Finally, the author describes the 20th century, marked by the constitutionalization of the administration and the review of the law itself, and the contemporary legality, marked by stronger demands that go beyond the simple conformity to the statutory law to reach the very justification of the administrative acts.

Keywords: Legality. Public Administration. 19 th century.

${ }^{1}$ Obra original: SORDI, Bernardo. Legge e amministrazione: incontri e scontri. In: STORTI, Claudia (a cura di). Le legalità e le crisi della legalità. Torino: G. Giappichelli, 2016. p. 171-179.

Recebido em: 05/10/2018

Revisado em: $31 / 10 / 2018$

Aprovado em: 04/11/2018

Direito autoral e licença de uso: Este artigo está licenciado sob uma Licença Creative Commons.Com essa licença você pode compartilhar, adaptar, para qualquer fim, desde que atribua a autoria da obra, forneça um link para a licença, e indicar se foram feitas alterações. 


\section{Premissa}

As legalidades e as crises das legalidades. É muito notável esse título no plural do nosso congresso.

Se o princípio de legalidade deve ser entendido "como norma de reconhecimento do direito vigente" e como "critério exclusivo de identificação do direito válido", teremos uma extrema dificuldade de sair não só do recinto da modernidade, mas mesmo de uma de suas declinações específicas, o Estado de direito europeu continental.

Ainda dois corifeus da modernidade, como Bodin e Domat, continuam a usar como categoria fundadora do próprio universo jurídico a distinção entre direito e lei ${ }^{3}$ e entre leis imutáveis e leis arbitrárias, que nada mais são que "aquelas que estabelecem aqueles que têm o poder de fazer as leis".

O legicentrismo, visto da margem do antigo regime, ainda é uma meta distante.

A legalidade, na acepção há pouco recordada do teórico geral, não pode então ser historicamente situada. Não pode ser a cômoda invariante que atravessa intacta a sucessão das experiências jurídicas. A legalidade, que abraça e monopoliza a totalidade das expressões do direito, não é predicável antes da fratura revolucionária.

Não só. A legalidade, no dia seguinte a essa fratura, não foi adquirida de uma vez por todas, nem se declina da mesma forma e com os mesmos conteúdos nos diversos ramos do direito; a legalidade permanece plural e plurais continuam as suas crises. Incessante o seu movimento.

\footnotetext{
${ }^{2}$ Uso a definição de L. FERRAJOLI, Principia iuris. Teoria del diritto e della democrazia, vol. II, Teoria della democrazia, Roma-Bari, Laterza, 2007, pp. 29-30.

${ }^{3}$ BODIN, I sei libri sullo Stato, traduzione italiana a cura di Margherita Isnardi Parente, vol. I, Torino, Utet, 19882, L.I, cap. VIII, p. 395: “direito e lei são duas coisas bem diversas entre si: o direito diz respeito à equidade e a lei comporta o comando: essa não é outra coisa senão o comando do soberano no exercício do seu poder".

${ }^{4}$ J. DOMAT, Traité des loix, in Les Loix civiles dans leur ordre naturel, Le Droit Public et Legum Delectus, Paris, Durand, 1777, vol. I, cap. XI, pp. XII ss.
} 
Assim, no universo civilístico, desde o plano napoleônico, o absolutismo jurídico media a rígida tomada de posse sobre as fontes do direito, com a intangibilidade da propriedade e do contrato, com o valor materialmente constitucional do estatuto civilístico. O celebérrimo texto do primeiro parágrafo do Code civil - "as convenções legalmente formadas tem o lugar de lei para aqueles que as fizeram" ("les conventions légalement formées tiennent lieu de loi à ceux qui les ont faites") - é uma verdadeira obra-prima normativa, na sua capacidade de manter juntos o primado indiscutível da lei (que a proposição normativa repete duas vezes) e o primado, igualmente indiscutível, da autonomia privado, daquele contrato finalmente liberado do jugo da tipicidade.

Mas até o universo civilístico, o mais equilibrado por quase todo o curso do século jurídico, está longe de ser imóvel. Já em 1899, Gény se lança contra "este fetichismo da lei escrita e codificada" ("ce fétichisme de la loi écrite et codifiée") que tende "a reduzir a ciência a um papel puramente mecânico" ("à reduire la science à un rôle purement mécanique")5. Diante da "legislação propriamente dita" ("législation proprement dite"), "manifestamente impotentes para acompanhar a evolução incessante das necessidades jurídicas" ("manifestement impuissante à suivre d'un pas égal et sûr l'évolution incessante des nécessités juridiques"), é agora necessário que o jurista adote "um Método, ao mesmo tempo amplo e flexível, de modo que pertença somente à ciência definir os processos e fixar as leis" ("une Méthode, à la fois large et souple, dont il appartient à la science seule de définir les procédés et des fixer le lois") ${ }^{6}$.

Mesmo no sistema codificado, "o último envelope formal do texto legal" ("derrière l'enveloppe formelle du texte legal"), os juristas descobrem cedo um retículo de "fontes menos formais e mais plásticas" ("sources moins formelles et plus plastiques") ${ }^{7}$, que contornam a lei e tornam plural o tecido normativo da ordem jurídica.

${ }^{5}$ F. GENY, Méthode d'interprétation et sources en droit privé positif, Paris, 1899. Citamos da reimpressão da segunda edição (1919), Paris, L.G.D.J., 1954, n.35, vol. I, p. 70; n. 36, vol. I, p. 72.

${ }^{6}$ Ibid., Introduction, n. 3, vol. I, p. 7.

${ }^{7} \mathrm{~F}$. GENY, Science et technique en droit privé positif. Nouvelle contribution à la critique de la méthode juridique, Paris, Sirey, 1922, n. 8, p. 27. Uma releitura problematizante, 
Tanto que, em 1902, Adhémar Esmein, no ensaio que abre o primeiro número da Revue trimestrielle de droit civil - não hesita em proclamar que é a jurisprudência "a verdadeira expressão do direito civil" ("la véritable expression du droit civil"), "a lei real e positiva" ("la loi réelle et positive" $)^{8}$. A simplicidade tão rapidamente construída, com igual rapidez se perde.

O penal, por seu turno, forte na longa incubação setecentista do modelo iluminista e do princípio de legalidade ${ }^{9}$, encontra já a poucas semanas da Bastilha uma completa formulação normativa no art. $8^{\circ}$ da declaração dos direitos: "a lei deve estabelecer somente penas estrita e evidentemente necessárias e ninguém pode ser punido senão em virtude de uma lei estabelecida e promulgada anteriormente ao delito, e legalmente aplicada". Praticamente a mesma formulação que, mesmo no cume de um percurso histórico muito tumultuado ${ }^{10}$, que passou pelas cartas oitocentistas (art. 4 das cartas francesas de 1814 e 1830; art. 26 do Estatuto Albertino*), reencontramos, pouco menos de dois séculos mais tarde, nos textos constitucionais da segunda metade do século XIX, da nossa constituição republicana (art. 25) à declaração universal dos direitos do homem de

in P. GROSSI, Pagina introduttiva (Ripensare Gény), in Quaderni fiorentini per la storia del pensiero giuridico moderno, 20 (1991), François Gény e la scienza giuridica del Novecento, pp. 1 ss.

${ }^{8}$ A. ESMEIN, La jurisprudence et la doctrine, in Revue trimestrielle de droit civil, I (1902), p. 12.

${ }^{9}$ Uma restrita legalidade, que já estava sancionada nos $\S \S 1,13,19$ da Josefina de 1787 (código geral sobre os delitos e as penas). Uma pontual contextualização em A. CAVANNA, Storia del diritto moderno in Europa. Le fonti e il pensiero giuridico, tomo 2, Milano, Giuffrè, 2005, p. 292 ss.

${ }^{10} \mathrm{M}$. SBRICCOLI, La penalistica civile. Teorie e ideologie del diritto penale dell'Italia unita, ora in ID., Scritti di storia del diritto penale e della giustizia. Scritti editi e inediti (1972-2007), Milano, Giuffrè, 2009, pp. 522 ss.; L. LACCHË, La penalistica costituzionale e il 'liberalismo giuridico'. Problemi e immagini della legalità nella riflessione di Francesco Carrara, in Quaderni fiorentini, 36 (2007), pp. 623 e ss. Imprescindível a contribuição do debate atual da penalística. Vejam-se pelo menos: F. PALAZZO, Legalità penale: considerazioni su trasformazione e complessità di un principio 'fondamentale', ibid., spec. p. 1285 e pp. 1321-23; G. FIANDACA, Il diritto penale fra legge e giudice, Padova, Cedam, 2002; M. DONINI, Il volto attuale dell'illecito penale. La democrazia penale tra differenziazione e sussidiarietà, Milano, Giuffrè, 2004. 
1948 (art.11), à convenção europeia dos direitos do homem de 1950 (art. 7), até a Carta de direitos (art. 49).

Nada disso acontece, contudo, no mundo novo da administração moderna.

A história da legalidade administrativa será muito pouco a história de proclamações do legislador constituciona ${ }^{11}{ }^{1}$ : constituinte demasiado parco, mesmo no século XX, em definir "as bases constitucionais do direito administrativo" ("les bases constitutionnelles du droit administratif") ${ }^{12}$. A nossa própria constituição republicana, pobre em enunciados sobre a administração, confirma que só uma leve veste constitucional recobre o nosso princípio.

A história da legalidade administrativa, de resto, só em parte é uma história normativa; em vez disso, ela é prevalentemente uma história conceitual, segundo um percurso pontuado, entre a virada do século XVIII e o presente, por uma inumerável série de encontros e desencontros.

Desse percurso, procuro isolar, de modo muito esquemático ${ }^{13} \mathrm{e}$ em rápida sucessão, pelo menos três grandes etapas sete e oitocentistas, antes de dar uma fugidia olhada no século XX e, ainda mais rapidamente, no presente. Definirei respectivamente essas três etapas: legalidade-poder; legalidade-garantia; legalidade-sistema.

${ }^{11}$ Constituem parciais exceções algumas constituições do século XX: a constituição austríaca de 1920 (art. 18); o Grundgesetz alemão (art. 20); a constituição espanhola de 1978 (art. 9).

12 G. VEDEL, Les bases constitutionnelles du droit administratif, in Conseil d'Etat. Etudes et documents, 8 (1954), pp. 21 ss. Mais recentemente, T.GINSBURG, Written Constitutions and administrative State: on the constitutional character of administrative law, in S.R. ACKERMAN, P. LINDSETH (eds.), Comparative Administrative Law, Cheltenham, UK-Northampton, Mass., Elgar, 2010, pp. 117-127.

${ }^{13}$ Para um tratamento mais aprofundado, remeto a L. MANNORI, B. SORDI, Storia del diritto amministrativo, Roma-Bari, Laterza, 2001; SORDI, Il principio di legalità nel diritto amministrativo che cambia. La prospettiva storica, in Diritto amministrativo, XVI (2008), pp. 1-28, nos quais são tratadas grande parte das considerações desenvolvidas neste texto. 


\section{Legalidade-Poder}

Essa primeira etapa coincide com o próprio momento revolucionário. A proclamação da lei como expressão da vontade geral traça as coordenadas de uma legalidade que marca por inteiro as relações entre os poderes e as funções. O primado da lei é absoluto. As funções de legis executio (que, de fato, de agora em diante se dirão subordinadas) são submetidas à legis latio da vontade geral. Revela-o bem a constituição de 1791: "não existe na França autoridade superior àquela da lei. O rei reina somente em função dela, e só em nome da lei pode exigir obediência" (art. $3^{\circ}$, tit. III, sec. I).

Aquilo que ainda falta, por outro lado, é uma específica projeção individual, sobre o plano das garantias, de um princípio de legalidade que exatamente por isso possa-se dizer administrativo. Entretanto, a administração, como sujeito dotado de poderes imperativos, está ainda, em boa parte por acontecer. Da mesma forma, a própria noção de acte administratif, na sua acepção tipicamente oitocentista de ato de império. $\mathrm{Na}$ Déclaration de 1789, a administração continua, de fato, a ser vista como simples execução "material" do ditame legal, com a função precípua de perceber e gerir a "contribuição comum", oferecendo a necessária prestação de contas (arts. 13, 14 e 15). Mais que isso não parece necessário ao constituinte para um poder que ainda não é visto como tal.

Na Declaração, ainda dominada pelo mito da administração como atividade material e pelo primado de uma lei que ainda se crê que possa se autoexecutar por meio da sociedade dos cidadãos ativos, chamados a desenvolver em primeira pessoa as funções públicas, uma específica legalidade administrativa - entendida como necessária delimitação legislativa dos poderes administrativos, tutelando os direitos e os interesses individuais - não é, portanto, proclamada.

De um lado, a administração é absorvida e confundida no rígido legicentrismo revolucionário: em um Estado legislativo, fundado sobre a separação dos poderes, nenhum poder pode passar por cima de uma lei que exprime por definição a volonté générale. 
Por outro lado, ainda que a Declaração tenha confiado à lei a tarefa de preservar a liberdade e a propriedade (arts. $4^{\circ}$ e 17 ), não chega, todavia, a exprimir os conteúdos garantistas próprios do paralelo princípio penal, já que a construção do poder administrativo e das relativas garantias havia começado há pouco, de modo progressivo, mas fragmentário, e o seu conteúdo é então absolutamente indeterminado.

Ocorre, portanto, uma diferença fundamental entre justiça e administração: se o pressuposto de um necessário fundamento legal para o exercício do poder público já está completamente adquirido pela função judiciária, segundo um modelo silogístico que a rápida escolha pela codificação é destinada ulteriormente a enfatizar, isso deve ainda se desdobrar na sua substância administrativa.

No aspecto administrativo da legalidade, premida por uma rígida ideologia separatista, ela tem dificuldade em encontrar o plano da tutela. O principal controle de legalidade, neste momento, é de tipo interno. Mas os próprios poderes de anulação e suspensão descontam a radical desconfiança da Assembleia contra o executivo e impedem até mesmo a formação de uma hierarquia administrativa.

Será o completo hiato entre justiça e administração que cunhará, entre a Revolução e o início do século XIX, as características tipicamente administrativas de uma legis executio completamente diferente da judiciária: fixado o indiscutível primado da lei, a persistente desconfiança contra o judiciário acompanhará o adensamento sobre a administração de poderes imperativos gerais e, ao mesmo tempo, o desenvolvimento dos primeiros núcleos do contencioso.

\section{Legalidade-Garantia}

A segunda etapa coincide com os primeiros fundamentos do Estado de direito. É o pensamento liberal, no início do século XIX, que impulsiona uma redefinição dos instrumentos de tutela. A perigosa deriva da soberania, dramaticamente revelada no Terror, dissolveu a harmonia pré-estabelecida entre soberania e direitos. As declarações de direitos não são mais suficientes. "São necessárias garantias positivas", proclama 
Benjamin Constant em 1815. "Uma autoridade não é legítima a não ser nos seus limites"14.

O princípio de legalidade gira em torno da garantia dos direitos individuais e começa a tomar forma teórica em uma ordem jurídica inteiramente estatalizada: exatamente à lei, instrumento essencial daquele poder que procura incansavelmente se firmar, confia-se a principal garantia dos direitos.

O problema dos limites obviamente não é novo. Nova é, por outro lado, a mediação entre poder e liberdade; novas são as técnicas de limitação da autoridade. As garantias que se invocam no início do século XIX são muito diversas daquelas, materiais e substanciais, típicas da ordem antiga. Os direitos abandonaram a sua intrínseca desigualdade e o seu histórico particularismo; não mais preexistem ao Estado; convivem com a soberania, com uma soberania impessoalizada pela centralidade da lei. $\mathrm{O}$ direito se identifica na lei e a lei se torna a principal garantia dos direitos.

Um valor novo, formal, de conformidade à lei - a legalidade, exatamente - começa a se tornar um predicado dos poderes públicos. Deste momento em diante, uma fonte legal é o pressuposto necessário de toda manifestação da autoridade. O novo templo do Estado de direito se assenta sobre a arquitrave da legalidade: uma arquitrave que já sustenta inteiramente a jurisdição e que inicia agora a construir-se também para a administração.

Não se trata de uma batalha certa. Encontros e desencontros se entrelaçam continuamente. O problema de como garantir a legalidade da administração é um problema que a própria Revolução deixou substancialmente aberto e que a construção napoleônica de um Estado fundado na administração pública aguçou sensivelmente.

O século XIX, de fato, redimensionou drasticamente o legicentrismo revolucionário da vontade geral e arquivou o ideal de uma autoadmi-

${ }^{14}$ B. CONSTANT, Principes de politique [1815], in ID., Euvres. A. ROULIN (Org.), Paris, Gallimard, 1957, p. 1198. ID., Cours de politique constitutionnelle, Bruxelles, Hauman, 18373, p. 110. 
nistração da sociedade. A separação entre justiça e administração se traduziu em uma imunidade geral ao controle jurisdicional. A administração não é mais composta de cidadãos ativos; se fez sujeito, burocratizou-se, estatalizou-se; redescobriu as formas comissariais dos antigos intendentes. Definitivamente separada da justiça, conquistou um poder geral de comando e, ao mesmo tempo, uma sólida centralidade institucional, a ponto de apresentar-se, entre os poderes públicos, como a verdadeira "essência do Estado".

A administração reivindica liberdade e autonomia; a sua ação "incessante" se desenvolve em um panorama legislativo presidido por poucas leis e que se demonstrará totalmente refratário a qualquer possibilidade de codificação. O campo da "administração pura" se ergue, por definição, como um grande espaço de poder distante da cobertura normativa da lei e resistente ao controle jurisdicional.

Até mesmo na cultura jurídica francesa, que invariavelmente declina a administração como "execução das leis" ("exécution des lois"), aparecendo como "poder executivo em ação" ("puissance exécutive en action"), como "a ação vital do governo" ("l'action vitale du gouvernement" ${ }^{15}$. Em nível de definição, a submissão à lei está fora de questão, mas "o interesse público ficaria comprometido por uma legislação de suspeita que, amordaçando a administração, recusa a ela a liberdade de se mover" ("l'intérêt public serait compromis par une législation soupçonneuse qui, garrottant l'administration, lui refuserait la liberté de se mouvoir" ". Como intérprete direto do interesse geral, na gestão do "imenso domínio" ("domaine immense") que conquistou, "a administração precisa de ar e de espaço; a liberdade é a sua vida" ("l'administration a besoin d'air et d'espace; la liberté est sa vie") $)^{17}$.

É o século XIX, então, que descobre a administração como poder e também como campo a ser juridicizado, que afirma a imperatividade da lei e, logo ao lado, o espaço de um controle de tipo jurisdicional, fazendo, em uma palavra, da legalidade administrativa uma questão de garantia.

${ }^{15}$ L.-M.-A. MACAREL, Cours de droit administratif, Paris, Thorel, 18482, vol. I, p. 11.

${ }^{16}$ A.-F.-A. VIVIEN, Etudes administratives, Paris, Guillaumin, 18522, t. I, p. 12.

${ }^{17}$ Ibid., p. 122. 
Como se dirá em várias retomadas e em diversos contextos nacionais, de Barthold Georg Niebuhr a Rudolf von Gneist e a Silvio Spaventa, até, do outro lado do Atlântico, com Woodrow Wilson: "a liberdade hoje deve ser procurada não tanto na constituição e nas leis políticas quanto na administração e nas leis administrativas".

É uma afirmação significativa. Por um lado, confirma que não haverá espaço, por todo o século, para garantias contra a lei. Do outro, revela que, onde foi mais forte e incisiva a construção do poder - como no universo administrativo -, lá é mais advertida e urgente a necessidade de se dispor de garantias eficazes dos direitos. Justiça e legalidade na administração - "aquilo que os alemães chamam de Rechtsstaat", como sintetiza em Bergamo, em maio de 1880, Silvio Spaventa - tornam-se as bandeiras do século.

Bandeiras sob cujos panos se fixam também alguns célebres pilares normativos, do art. $5^{\circ}$ da seção $\mathrm{E}$ da lei de 20 de março de 1865 - sobre a não aplicação dos atos administrativos em desconformidade com a lei - à tríade dos vícios acionáveis diante da quarta seção [N.T.: do Conselho de Estado], fixada em 1889, até o art. 11 do Staatsgrundgesetz austríaco de 1867 sobre o fundamento legislativo das ordens e regulamentos.

A legalidade-poder lentamente se tornou legalidade-garantia.

\section{Legalidade-Sistema}

A terceira etapa coincide com a definitiva fundação do regime administrativa.

A legalidade-garantia conserva, durante grande parte do século XIX, uma projeção pontual. Só um droit privatif, um droit acquis, um "direito civil e político" legitima a ativação de um controle jurisdicional: a cobertura da lei abraça só alguns pequenos escólios no mar da administração pura. Até o controle que se ativa em seu nome segue as formas, e não a substância, do agir administrativo. O contencioso francês e o controle pelo juiz ordinário da nossa lei de abolição do contencioso em 1865 inspiram-se nessa lógica. 
Mas a legalidade não é imóvel, nem vive só da dimensão conceitual.

O Estado de direito está conquistando, em grande parte da Europa continental, a sua efetividade institucional. O definitivo enraizamento de sistemas de justiça administrativa completos tem um notável efeito de impulso: a legalidade está se tornando, cada vez mais, legitimidade administrativa. O caminho é muito evidente na França entre o Segundo Império e a Terceira República, com o notável sucesso do recurso por excesso de poder, mas é igualmente estratégica, seja na Itália, seja nos países de língua alemã.

Nenhum percurso constitucional acompanha a consolidação das garantias no terreno administrativo; até mesmo a individualização é modesta: bastaria recordar aquela francesa sobre o caráter subjetivo ou objetivo do recurso por excesso de poder, ou o próprio nascimento do interesse legítimo na Itália. A legalidade está, contudo, ampliando o seu guarda-chuva a partir do interior da organização administrativa, desenvolvendo a garantia toda objetiva, típica do processo de recurso, contra a "verdadeira ilegalidade" ("véritable illegalité").

É pobre, pelo menos diante de nossos olhos com fortes valores constitucionais, essa declinação oitocentista do princípio de legalidade cujos destinos entrelaçam-se cada vez mais com a especialidade administrativa. Isso acontece no terreno jurisprudencial e no dogmático. É neste momento que o princípio da legalidade, nas mãos de juristas em busca de uma verdadeira parte geral do direito administrativo, revela uma formidável "função ordenadora".

É o momento da grande elaboração continental dos princípios do direito administrativo; o momento da apoteose da especialidade: é o decreto que, com a sua carga de imperatividade, declara aquilo que é o direito no caso concreto, a tornar justiçável a pretensão a uma administração segundo a lei, a uma administração legítima.

O princípio de legalidade, no direito administrativo, não constitui, então, a projeção vitoriosa de um parlamento irresistivelmente lançado à conquista dos espaços típicos da discricionariedade administrativa. É a própria estrutura da legitimidade, base indefectível da especialidade-ga- 
rantia típica do modelo continental, que encontra - quase paradoxalmente - os seus artífices principais e suas fontes longe do legislador.

São, em primeiro lugar, os juristas, na sua dupla articulação de $d o c$ trine jurisprudentielle e de doctrine enseignante ${ }^{18}$, que modelam os princípios gerais de uma administração segundo a lei.

O próprio "poder dos doutores" ("pouvoir des docteurs") contribui para definir em concreto as conotações essenciais do État de droit: "sem essa capitalização das doutrinas" ("sans cette capitalisation des doctrines"), já notava Pierre Legendre, "o direito administrativo teria continuado a ser uma prática da administração, mais ou menos incontrolável e incontrolada" ("le droit administratif serait resté une pratique de l'administration, plus ou moins incontrôlable et incontrôlée" $)^{19}$. O Estado de direito, no modelo continental, conserva uma inequívoca matriz doutrinária $^{20}$.

\section{A Legalidade Novecentista}

$\mathrm{O}$ século $\mathrm{XX}$ abre cenários novos, inéditos, inclusive para o nosso princípio. Com o advento das constituições democráticas, o legislador constitucional começa a dar uma direta roupagem normativa ao princípio da legalidade. É o caso, já lembrado, do art. 18 da constituição austríaca de 1920, que, a partir das contribuições da Escola de Viena, proclama: “toda a administração estatal só pode ser exercida com base na lei". O princípio da legalidade administrativa, pela primeira vez, se torna expressão do poder constituinte e eixo de rolamento de uma república que se define "democrática" e na qual "o direito deriva do povo" (art. 1): uma

\footnotetext{
18 Segundo uma célebre distinção de J. RIVERO, Jurisprudence et doctrine dans l'élaboration du droit administratif, in Conseil d'Etat. Etudes et documents, 9 (1955), p. 35.

19 P. LEGENDRE, La facture historique des systèmes. Notations pour une histoire comparative du droit administratif français, in Revue international de droit comparé, 23 (1971), p. 26.

${ }^{20}$ Desenvolvemos esses temas em Sur la valeur normative de la doctrine juridique dans le système administratif, in Droits, 60 (2014), pp. 169 ss.
} 
reserva legal total cobre por inteiro o exercício da função. Fórmulas conotativas, como se viu, destinadas a ser retomadas no segundo pós-guerra, e que, ainda que com certa lentidão, demonstraram possuir um grande alcance, impulsionando a codificação do procedimento ${ }^{21}$ e do processo administrativos, rumo ao abandono da colateralidade entre juiz e administração, abrindo também a jurisdição administrativa às regras do devido processo, suavizando definitivamente, assim, os resíduos autoritários do regime administrativo oitocentista.

O longo século XX, não pode ser, no entanto, de nenhuma forma abreviado. Os caminhos da democracia na administração se interrompem continuamente. Um cenário constrangedor seria aquele oferecido pelo Doppelstaat. Mas não há tempo para fazer uma incursão sobre os encontros e desencontros que envolvem legalidade e totalitarismos. Limito-me a recordar que será a experiência traumática do período entre as duas guerras que agitará, pela primeira vez, a fé até então inquebrantável no valor da legalidade, desencadeando uma turbação sem precedentes na consciência dos juristas e desnudando certas tautologias oitocentistas. Revela-o - estamos em agosto de 1943 - um sacerdote da legalidade como Piero Calamandrei: "só nós com a magistratura vivemos esse tormento das leis que se esmigalham como papel machê velho entre as mãos de quem queria dele se servir"22; enquanto, no prefácio a Beccaria, escrito no inverno de 1943-44, no refúgio de Collicello Umbro, escreve outra frase marcante: "na moldura da legalidade, pode-se colocar ouro ou chumbo" 23. Um perigo que a segunda metade do século XX soube evitar ampliando até sobre a lei o campo da justiçabilidade ${ }^{24}$.

Abreviadas forçosamente as etapas novecentistas, limito-me a dar uma brevíssima olhada no presente.

\footnotetext{
${ }^{21}$ Assim o art. $1^{\circ}, \S 1^{\circ}$ da lei de 7 de agosto de 1990, $n^{\circ} 241$ : "a atividade administrativa persegue os fins determinados pela lei...".

${ }^{22}$ P. CALAMANDREI, Gli avvocati e la libertà, in Corriere della sera, 25 agosto 1943, ora in ID., Opere giuridiche, vol. II, Napoli, Morano, 1966, p. 419.

${ }^{23}$ P. CALAMANDREI, Prefazione a C. BECCARIA, Dei delitti e delle pene, a cura dello stesso Piero Calamandrei, Firenze, Le Monnier, 1945, p. 92.

${ }^{24} \mathrm{G}$. ZAGREBELSKY, La legge e la sua giustizia. Tre capitoli di giustizia costituzionale, Bologna, Il Mulino, 2008.
} 
A arquitrave da legalidade entoava um preciso nexo entre autoridade e liberdade; pressupunha um legislador como árbitro exclusivo do confronto; uma representação das fontes do direito, igualmente simplificada na drástica equiparação entre direito e lei; uma substancial alteridade entre justiça e administração; um modelo essencialmente impugnatório e cassatório de justiça administrativa.

$\mathrm{Na}$ realidade do universo administrativo oitocentista, como se viu, os equilíbrios efetivos não corresponderam de todo ao modelo: o absolutismo jurídico conseguiu penetrar muito relativamente e a administração permanecia uma terra sem código.

Fechadas as grandes coordenadas revolucionário-napoleônicas, o regime administrativo se definiu por meio de uma forte interação entre jurisprudência e doutrina, à qual o legislador - confinado a algumas grandes leis de organização administrativa - permanecia substancialmente estranho.

As três etapas que individualizamos - legalidade-poder; legalidade-garantia; legalidade-sistema - deixaram traços profundos no ordenamento. Nenhuma delas foi definitivamente superada; cada etapa é ainda reconhecível.

Há mais disposição em reconhecer, de novo, uma crescente discrepância entre lei e direito, o retorno aos princípios gerais de gênese não-legislativa (também por força da penetração de um direito europeu de indelével trama jurisprudencial); a desancorar a legalidade do estreito abraço com a lei e a considerá-la como regra de direito: de um direito sempre mais plural e multinormativo, marcado, em contrapartida, portanto, por uma renovada "incerteza" 25 .

A legalidade não é mais um pilar, mas, como dizem eficazmente os filósofos do direito, tornou-se um "tecido"26: elástico, com franjas, aberto

${ }^{25}$ P. GROSSI, Sulla odierna 'incertezza' del diritto, in Giustizia civile, 2014, fasc. 4, pp. 921 ss.

${ }^{26}$ Segundo a feliz imagem de M. VOGLIOTTI, Legalità, in Enc. dir., Annali, VI, Milano, Giuffrè, 2013, p. 420. 
mais à osmose que à separação das funções; imerso em uma Rechtsfindung de corte tipicamente hermenêutico.

A administração se configurou como execução de leis respondendo ao imperativo de unidade de comando do Estado e às exigências de garantia individual, que tentei percorrer. Exatamente porquê escavado do sulco iluminista-revolucionário pelo qual "a liberdade ... tem como salvaguarda a lei" ("la liberté ... a pour sauvegarde la loi") (Declaração de 1793, art. $6^{\circ}$ ), o princípio de legalidade não pôde, contudo, deixar de falar sempre a "linguagem do poder".

Hoje, em um contexto de contração da especialidade administrativa, de nova expansão do direito comum, de transformação e pluralização dos modelos processuais, de um direito sempre mais plural e multinormativo, o quadro se tornou mais articulado.

Bem o revela o art. 41 da Carta dos Direitos da União Europeia, intitulado como direito a uma boa administração ${ }^{27}$.

A legalidade não pode ser a métrica exclusiva do agir administrativo. Ao antigo direito público subjetivo à legitimidade dos atos administrativos, ganha espaço um direito a uma boa administração e a um tratamento equânime e imparcial, que se especifica por meio de direitos de hearing, access, giving reasons, que evocam mais a justiçabilidade do que a legalidade da administração e que redescobre a oficina das coisas, a materialidade originária típica do administrar.

Certamente emerge a necessidade de projetar segundo outros termos e outros equilíbrios o grande fruto oitocentista da administração de garantia.

E também este é o sinal do mundo de ontem, de uma simplicidade rapidamente criada e também rapidamente perdida.

${ }^{27}$ Sobre essa « forme de protection procédurale », veja-se a convincente análise de L. AZOULAI, Le principe de bonne administration, in Droit administratif européen (dir. J.B. AUBY, J. DUTHEIL DE LA ROCHERE), Bruxelles, Bruylant, 2007, pp. 493 e ss. Um enquadramento problemático da démocratie d'impartialité está em P. ROSANVALLON, La légitimité démocratique. Impartialité, réflexivité, proximité, Paris, Seuil, 2008, pp. 139 ss. 


\section{Referências}

ACKERMAN, S. R.; LINDSETH, P. (Ed.). Comparative Administrative Law, Cheltenham, UK-Northampton. Mass: Elgar, 2010. p. 117-127.

CALAMANDREI, P. Prefazione de Beccaria. Dei delitti e delle pene, a cura dello stesso Piero Calamandrei. Firenze: Le Monnier, 1945. p. 92. CAVANNA, A. Storia del diritto moderno in Europa. Le fonti e il pensiero giuridico, tomo 2, Milano, Giuffrè, 2005, p. 292 ss.

DOMAT, J. Traité des loix, in Les Loix civiles dans leur ordre naturel, Le Droit Public et Legum Delectus. Paris : Durand, 1777. v. I, cap. XI, p. XII ss.

DONINI, M. Il volto attuale dell'illecito penale. La democrazia penale tra differenziazione e sussidiarietà. Milano: Giuffrè, 2004.

ESMEIN, A. La jurisprudence et la doctrine. Revue trimestrielle de droit civil, I, p. 12, 1902.

FERRAJOLI, L. Principia iuris. Teoria del diritto e della democrazia, v. II, Teoria della democrazia, Roma-Bari, Laterza, 2007. p. 29-30.

FIANDACA, G. Il diritto penale fra legge e giudice. Padova: Cedam, 2002.

GENY, F. Méthode d'interprétation et sources en droit privé positif. Paris, 1899.

GENY, F. Science et technique en droit privé positif. Nouvelle contribution à la critique de la méthode juridique. Paris: Sirey, 1922. n. 8 , p. 27.

GROSSI, P. Pagina introduttiva (Ripensare Gény), in Quaderni fiorentini per la storia del pensiero giuridico moderno, 20, 1991.

GROSSI, P. Sulla odierna 'incertezza' del diritto. Giustizia civile, fasc. 4, p. 921 ss., 2014. 
LACCHÈ, L. La penalistica costituzionale e il 'liberalismo giuridico'. Problemi e immagini della legalità nella riflessione di Francesco Carrara. Quaderni fiorentini, [S.l.], v. 36, p. 623 e ss., 2007.

LEGENDRE, P. La facture historique des systèmes. Notations pour une histoire comparative du droit administratif français. Revue international de droit comparé, [S.l.], v. 23, p. 26, 1971.

MACAREL, L. M. A. Cours de droit administratif. Paris: Thorel, 1848. V. I, p. 11.

MANNORI, L.; SORDI, B. Storia del diritto amministrativo. RomaBari: Laterza, 2001.

RIVERO, J. Jurisprudence et doctrine dans l'élaboration du droit administratif, in Conseil d'Etat. Etudes et documents, [S.l.], v. 9, 1955, p. 35 .

ROSANVALLON, P. La légitimité démocratique. Impartialité, réflexivité, proximité, Paris, Seuil, 2008. p. 139 ss.

SBRICCOLI, M. La penalistica civile. Teorie e ideologie del diritto penale dell'Italia unita, ora in ID., Scritti di storia del diritto penale e della giustizia. Scritti editi e inediti (1972-2007), Milano: Giuffrè, 2009.p. 522 ss.

VEDEL, G. Les bases constitutionnelles du droit administratif, in Conseil d'Etat. Etudes et documents, v. 8, p. 21, 1954.

VIVIEN, A. F. A. Etudes administratives. Paris: Guillaumin, 1852. t. I, p. 12.

VOGLIOTTI, M. Legalità, in Enc. dir., Annali, VI. Milano: Giuffrè, 2013. p. 420.

ZAGREBELSKY, G. La legge e la sua giustizia: tre capitoli di giustizia costituzionale. Bologna: Il Mulino, 2008. 
Bernardo Sordi é professor catedrático de História do Direito Medieval e Moderno na Università degli Studi di Firenze (UNIFI). De 2003 a 2012 dirigiu o Centro di Studi per la Storia del Pensiero Giuridico Moderno (UNIFI). Faz parte da redação dos Quaderni Fiorentini per la Storia del Pensiero Giuridico Moderno. E-mail: bernardo.sordi@unifi.it

Endereço profissional: Università degli Studi di Firenze, Dipartimento di Scienze Giuridiche, Via delle Pandette, 32, Firenze, FI, Itália, CAP: 50127.

Arthur Barrêtto de Almeida Costa é bacharel e mestrando em Direito pela Universidade Federal de Minas Gerais (UFMG), membro do Studium Iuris Grupo de Pesquisa em História da Cultura Jurídica (UFMG/CNPq).

E-mail: arthurbarretto@oi.com.br

Endereço profissional: Universidade Federal de Minas Gerais, Faculdade de Direito, Av. João Pinheiro n. 100, Centro, Belo Horizonte, MG, Brasil. CEP: 30130-180. 